\title{
Phylogenetic analysis and siderotyping as useful tools in the taxonomy of Pseudomonas stutzeri: description of a novel genomovar
}

Correspondence

Elena García-Valdés elena.garciavaldes@uib.es

\author{
Magdalena Mulet, ${ }^{1}$ Margarita Gomila, ${ }^{1}$ Christelle Gruffaz, ${ }^{2}$ \\ Jean-Marie Meyer, ${ }^{2}$ Norberto J. Palleroni, ${ }^{3}$ Jorge Lalucat ${ }^{1}$ \\ and Elena García-Valdés ${ }^{1}$
}

\author{
${ }^{1}$ Departament de Biologia, Microbiologia and Institut Mediterrani d'Estudis Avançats (CSIC-UIB), \\ Universitat de les Illes Balears, Campus UIB, 07122 Palma de Mallorca, Spain \\ ${ }^{2}$ Département Environnement, Génétique Moléculaire et Microbiologie, UMR 7156 Université \\ Louis-Pasteur/CNRS, 28 rue Goethe, 67000 Strasbourg, France \\ ${ }^{3}$ Department of Biochemistry and Microbiology, Rutgers University, Cook Campus, New Brunswick, \\ $\mathrm{NJ}$, USA
}

\begin{abstract}
An examination of the results of phylogenetic analyses based on the sequences of fragments of the 16S rRNA, gyrB and rpoD genes, and the discrimination of genomovars based on siderophore diversity within the genus Pseudomonas, has added important taxonomic tools in the characterization of Pseudomonas stutzeri. Eighteen reference strains, nine newly identified hydrocarbon-degrading strains and three strains showing relevant physiological characteristics of $P$. stutzeri, together with the type strains of four related species, were included in the study. A novel genomovar within the species is described. A summary of the methodology used in these studies and the results of our attempts to define a solid internal subdivision of this important species within the genus Pseudomonas are presented and discussed.
\end{abstract}

Pseudomonas stutzeri is a species of extremely broad phenotypic and genotypic diversity which has been subjected to intensive studies including substrate assimilation tests, determination of cellular component profiles (whole-cell and outer-membrane proteins, lipopolysaccharides, fatty acids), multilocus enzyme electrophoresis studies as well as nucleic acid sequence similarity studies and multilocus sequence analysis (MLSA). Integration of these studies with the results of DNA-DNA hybridization justifies the recognition of 17 genomic groupings (genomovars) within the species (Lalucat et al., 2006). In recent times, taxonomic studies based on the diversity of siderophores produced by members of the various groups of pseudomonads have resulted in the development of powerful determinative techniques at the species level (Meyer et al., 2002, 2007; Meyer, 2007). Zawadzka et al. (2006) studied siderophore production among members of

Abbreviation: MLSA, multilocus sequence analysis.

The GenBank/EMBL/DDBJ accession numbers for the sequences determined in this study are AM905851-AM905859 (16S rRNA gene), AM905860-AM905873 and AM939370-AM939377 (rpoD) and AM905825-AM905838 and AM939378-AM939385 (gyrB).

Details of strains, primers and sequence accession numbers and consensus similarity indices are available as supplementary material with the online version of this paper. nine genomovars of $P$. stutzeri and also the presence of ferrioxamine outer-membrane receptor genes in these strains. Consequently, siderophore production has been examined in all 17 reference strains and in nine novel hydrocarbon-degrading isolates included in the present study. The studies reported here are extended to (i) the results of Cladera et al. (2004) demonstrating the monophyletic origin of eight genomovars described by Sikorski et al. (2005), as well as the agreement of phylogenetic affiliation through DNA-DNA relatedness analysis, and (ii) the determination and validation of siderotyping and DNA relatedness studies as practical approaches for assigning new isolates of P. stutzeri to their corresponding genomovars within the species.

The strains of $P$. stutzeri studied are representative of widely separated geographical locations and were isolated by different procedures and from very different habitats (Table 1). Two strains of Pseudomonas balearica (former genomovar 6) and the type strain of Pseudomonas xanthomarina have been included in the study as representatives of closely related species. The outgroup was represented by the type strains of Pseudomonas mendocina and Pseudomonas aeruginosa. Alternative designations of strains studied are indicated in Supplementary Table S1 (available in IJSEM Online). 
Table 1. Bacterial strains used in this study

Ref, Reference strain of genomovar. Siderophore types are indicated as A (catecholate type) and B (desferri-ferrioxamine E). ND, Not detected; -, not done. Additional strain designations are detailed in Supplementary Table S1.

\begin{tabular}{|c|c|c|c|c|c|}
\hline Strain & $\begin{array}{l}\text { Genom- } \\
\text { ovar }\end{array}$ & $\begin{array}{l}\text { Sideropho- } \\
\text { re type }\end{array}$ & $\begin{array}{c}\text { Origin and/or physiological } \\
\text { characteristics }\end{array}$ & $\begin{array}{l}\text { Geographical } \\
\text { location }\end{array}$ & Reference \\
\hline \multicolumn{6}{|l|}{ P. stutzeri } \\
\hline CCUG $11256^{\mathrm{T}}$ & Ref gv. 1 & $\mathrm{~B}$ & Clinical & $\begin{array}{l}\text { Copenhagen, } \\
\text { Denmark }\end{array}$ & Lalucat et al. (2006) \\
\hline ATCC 17591 & Ref gv. 2 & B & Clinical & $\begin{array}{l}\text { Copenhagen, } \\
\text { Denmark }\end{array}$ & Lalucat et al. (2006) \\
\hline DSM 50227 & Ref gv. 3 & B & Clinical & Unknown & Lalucat et al. (2006) \\
\hline 19SMN4 & Ref gv. 4 & B & Marine & Barcelona, Spain & Lalucat et al. (2006) \\
\hline DNSP21 & Ref gv. 5 & B & Wastewater & Mallorca, Spain & Lalucat et al. (2006) \\
\hline DSM 50238 & Ref gv. 7 & A & Soil & California, USA & Lalucat et al. (2006) \\
\hline JM300 & Ref gv. 8 & A & Soil & California, USA & Rosselló-Mora et al. (1996) \\
\hline $\mathrm{KC}$ & Ref gv. 9 & B & Aquifer & California, USA & $\begin{array}{l}\text { Sepúlveda-Torres et al. } \\
\text { (2001) }\end{array}$ \\
\hline CLN100 & Ref gv. 10 & ND & Deposit of chemical production plant & Germany & Lalucat et al. (2006) \\
\hline $28 \mathrm{a} 50$ & Ref gv. 11 & ND & Soil & Israel & Sikorski et al. (2005) \\
\hline $28 \mathrm{a} 39$ & Ref gv. 12 & ND & Soil & Israel & Sikorski et al. (2005) \\
\hline $28 \mathrm{a} 22$ & Ref gv. 13 & ND & Soil & Israel & Sikorski et al. (2005) \\
\hline $28 \mathrm{a} 3$ & Ref gv. 14 & ND & Soil & Israel & Sikorski et al. (2005) \\
\hline $4 c 29$ & Ref gv. 15 & ND & Marine sediment & Germany & Sikorski et al. (2005) \\
\hline $24 \mathrm{a} 13$ & Ref gv. 16 & ND & Soil contaminated with mineral oil & Germany & Sikorski et al. (2005) \\
\hline $24 a 75$ & Ref gv. 17 & ND & Soil contaminated with mineral oil & Germany & Sikorski et al. (2005) \\
\hline MT-1 & Ref gv. 18 & ND & Mariana Trench & Japan & Sikorski et al. (2005) \\
\hline CCUG 46542 & Ref gv. $19^{*}$ & ND & Didemnum sp. (marine ascidian) & Maldives & Romanenko et al. (2005) \\
\hline ATCC 27951 & gv. 1 & $\mathrm{~B}$ & Yogurt & Algeria & Lalucat et al. (2006) \\
\hline st103 & gv. $5^{\star}$ & B & Phragmites australis rhizosphere & Unknown & This study \\
\hline st104 & gv. $5^{*}$ & B & Spartina patens rhizosphere & Unknown & This study \\
\hline $2 \mathrm{FA}$ & gv. $3^{*}$ & B & $\begin{array}{l}\text { Culture collection, Dept of Biochemistry } \\
\text { and Microbiology, Rutgers University }\end{array}$ & Unknown & This study \\
\hline st106A & gv. $3^{*}$ & B & $\begin{array}{l}\text { Spartina alterniflora rhizosphere; growth } \\
\text { with naphthalene and hexadecane }\end{array}$ & USA & This study \\
\hline st107A & gv. $3^{*}$ & B & $\begin{array}{l}\text { Soil; growth with naphthalene } \\
\text { and hexadecane }\end{array}$ & USA & This study \\
\hline st108A & gv. $3^{\star}$ & B & $\begin{array}{l}\text { S. alterniflora rhizosphere; growth } \\
\text { with naphthalene and hexadecane }\end{array}$ & USA & This study \\
\hline CCUG 36651 & gv. $3^{\star}$ & - & $\begin{array}{l}\text { Water, borehole; anaerobic growth } \\
\text { with ferric citrate without nitrate }\end{array}$ & Sweden & This study \\
\hline WM88 & gv. $3^{*}$ & - & $\begin{array}{l}\text { Soil enriched with phosphite; } \\
\text { hypophosphite and phosphite oxidizer }\end{array}$ & Urbana, IL, USA & Metcalf \& Wolfe (1998) \\
\hline 2FB7A & gv. $7^{\star}$ & A & $\begin{array}{l}\text { River sediment; growth with } \\
\text { 2-fluorobenzoate }\end{array}$ & Kyungan, Korea & Song et al. (2000) \\
\hline $4 \mathrm{FB} 3$ & gv. $7^{\star}$ & A & $\begin{array}{l}\text { Estuarine sediment; growth with } \\
\text { 4-fluorobenzoate }\end{array}$ & $\begin{array}{l}\text { Arthur Kill, } \\
\text { NJ, USA }\end{array}$ & Song et al. (2000) \\
\hline \multicolumn{6}{|l|}{ Other species } \\
\hline $\begin{array}{l}\text { P. xanthomarina CCUG } \\
46543^{\mathrm{T}}\end{array}$ & & ND & $\begin{array}{l}\text { Halocynthia aurantium } \\
\text { (marine ascidian) }\end{array}$ & Sea of Japan & Romanenko et al. (2005) \\
\hline P. balearica DSM $6083^{\mathrm{T}}$ & & A & Wastewater & Mallorca, Spain & Lalucat et al. (2006) \\
\hline P. balearica LS401 & & A & Marine & Barcelona, Spain & Lalucat et al. (2006) \\
\hline P. balearica st $101^{*}$ & & A & S. patens rhizosphere & Unknown & This study \\
\hline $\begin{array}{l}\text { P. mendocina ATCC } \\
25411^{\mathrm{T}}\end{array}$ & & - & Soil & Argentina & Lalucat et al. (2006) \\
\hline $\begin{array}{l}\text { P. aeruginosa CCM } \\
1960^{\mathrm{T}}\end{array}$ & & - & Unknown & Unknown & - \\
\hline
\end{tabular}

${ }^{\star}$ Assignment from this study. 
Culture media (Luria-Bertani medium; Miller, 1972) and growth conditions $\left(30{ }^{\circ} \mathrm{C}\right)$, procedures for DNA extraction and PCR amplification and DNA sequencing conditions have been described previously by Cladera et al. (2004). Primers used for 16S rRNA (1080 nt), gyrB (B subunit of gyrase, $849 \mathrm{nt}$ ) and $r p o D$ (D subunit of RNA polymerase, $786 \mathrm{nt}$ ) gene amplifications are indicated in Supplementary Table S2. The nucleotide sequences determined in this study have been deposited in the EMBL database. Other sequences used in the analysis have been deposited previously in public databases (strains and accession numbers are indicated in Supplementary Table S3).

Gene sequences were aligned with the closest relatives retrieved from the GenBank nucleotide sequence database. The alignment was done using a hierarchical method for multiple alignments implemented in the CLUSTAL_X computer program (Thompson et al., 1997). Automatically aligned sequences were checked manually. Similarities and evolutionary distances were calculated with programs implemented in PHYLIP (Felsenstein, 1989). Gene distances were calculated from nucleotide sequences by the JukesCantor method (Jukes \& Cantor, 1969). Dendrograms were generated by neighbour-joining, maximum-likelihood and bootstrap analyses (1000 replications), algorithms included in programs of the PHYLIP package. Topologies of the trees were visualized with the TreeView program (Page, 1996). In addition to individual trees of the $16 \mathrm{~S}$ rRNA, gyrB and $r p o D$ gene partial sequences for each bacterial strain (total length $2445 \mathrm{nt}$ ), a concatenated and a consensus analysis of the three genes were performed (Cladera et al., 2004) to represent the combined molecular evolutionary relationships. In brief, for the consensus analysis, the evolutionary analysis was performed by calculating the corresponding distance matrices for each gene, using the algorithm of Jukes \& Cantor (1969). Finally, a unique matrix of distances was obtained by averaging the resulting sets and used as an additional measure of divergence between strains. The consensus multilocus tree was calculated from the consensus multilocus matrix by the neighbour-joining method.

Phylogenetic Bayesian analyses were also conducted in a parallel version of MrBayes 3.1.2 available online at http:// cbsuapps.tc.cornell.edu/mrbayes.aspx. Each Bayesian search performed two independent runs of four chains, where each chain was run in a single node, giving eight in total. We assumed a GTR $+\mathrm{I}+\Gamma$ model, which was the optimal model to explain our data as estimated with MODELTEST, which compares 56 models of DNA sequence evolution, as described by Posada \& Crandall (1998).

Individual trees for the three genes considered in this study, as well as the concatenated and consensus trees, were constructed for the strains studied, together with other 16 strains studied previously (Cladera et al., 2004). Fig. 1 shows the dendrogram corresponding to the consensus analysis. All tree topologies were very similar, maintaining the groupings of strains. Individual trees are not shown. In the present study, three housekeeping genes have been selected from the seven analysed previously for MLSA studies: the 16S rRNA gene, necessary to affiliate the species phylogenetically, and two other housekeeping genes, rpoD and $g y r B$. They yield appropriately sized amplicons and low $\mathrm{d}_{\mathrm{N}} / \mathrm{d}_{\mathrm{S}}$ ratios (non-synonymous versus synonymous nucleotide substitutions) and have good discrimination power for different genomovars. Very good correlation was found between the similarity indexes determined for six genes and for three genes $\left(r^{2}=0.88\right)$, being almost equally discriminative in the consensus analysis (Fig. 2), indicating that analysis of the $16 \mathrm{~S}$ rRNA, gyrB and $r p o D$ genes is sufficient for proper phylogenetic discrimination. The consensus tree obtained corroborates the monophyletic origin of the genomovars within the Pseudomonas branch. A phylogenetic tree including the nine species of the $P$. aeruginosa complex, as defined by Yamamoto et al. (2000), also corroborated these results (not shown).

Reference strains of eight recently described genomovars (gv. 11 to gv. 18) were affiliated in independent subbranches as shown in Fig. 1. Six of the novel strains included in this study (CCUG 36651, WM88, st106A, st107A, st108A and 2FA) clustered clearly within genomovar 3. Strain st104 clustered with DNSP21 (reference strain of gv. 5) in all phylogenetic trees analysed. The closest genomovar reference strain for 2FB7A and 4FB3 was DSM 50238 (reference of gv. 7), close to AER 2.7, a recognized member of gv. 7. Strain st101 was affiliated with the $P$. balearica phylogenetic branch in all trees with bootstrap values of 1000. Strain CCUG 46542 did not cluster clearly in any described genomovar. P. xanthomarina was the only species included within the P. stutzeri consensus phylogenetic branch.

Members of the same genomovar clustered in the same phylogenetic sub-branch in all trees with only a few exceptions: in the $16 \mathrm{~S}$ rRNA gene tree, strains st103 and st108A did not cluster with any known genomovar, but, in the $\operatorname{gr} B, r p o D$, consensus and concatenated trees, they were clearly affiliated to gv. 5 and gv. 3, respectively. Two other exceptions were strain JD4 (a recognized member of gv. 5) in the rpoD and consensus trees and DSM 50238 (reference of gv. 7) in the gyrB tree, confirming a previous report (Cladera et al., 2004).

Supplementary Table S4 indicates the similarity indices obtained in the consensus matrix. It shows that all reference strains from eight recently described genomovars (gv. 11-18) have similarity values to their closest genomovar (88.6-94.9\%) in the same range found between the other ten genomovars (gv. 1-10, 92.1-95.2\%). Similarity values of $P$. stutzeri strains to the closest species are $83.3-87.3 \%$ (P. balearica), $78.0-82.6 \%$ (P. mendocina), 78.4-83.9\% (P. aeruginosa) and $84.3-91.5 \%$ ( $P$. xanthomarina). Minimal intragenomovar similarities were calculated for those genomovars in which more than one strain was studied (Supplementary Table S4) giving values of $98.8 \%$ (gv. 1), $99.7 \%$ (gv. 2), $97.7 \%$ (gv. 3), $100 \%$ (gv. 4), 


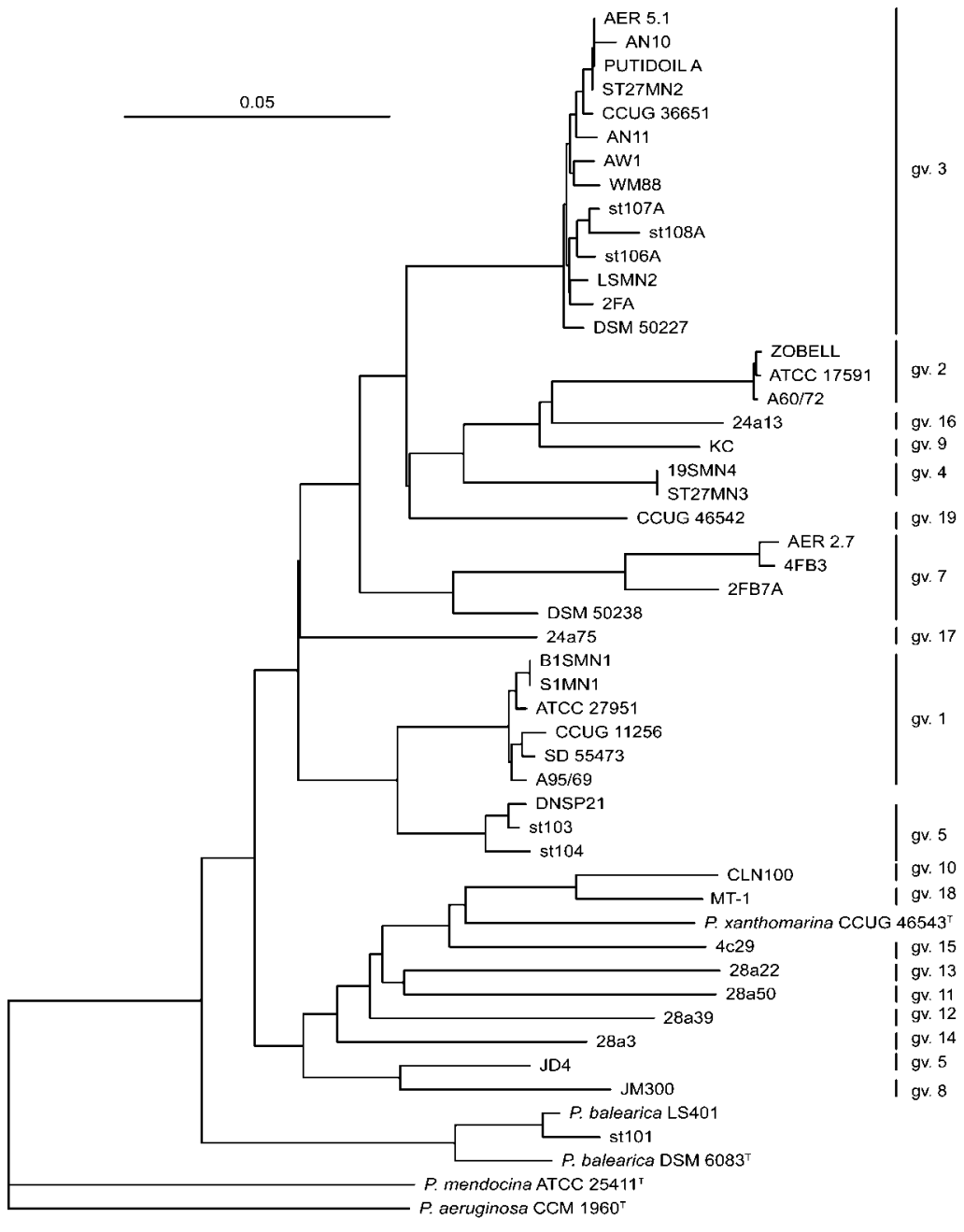

Fig. 1. Consensus dendrogram of $P$. stutzeri strains based on phylogenetic analysis of partial sequences of the 16S rRNA, gyrB and $r p o D$ genes. Bar, $5 \%$ sequence divergence. Sequence accession numbers for some strains are detailed in Supplementary Table S3.
$92.5 \%$ (gv. 5) and $91.5 \%$ (gv. 7). The similarity values for the 11 novel strains (not previously assigned to genomovars) to the closest genomovar reference strain were higher

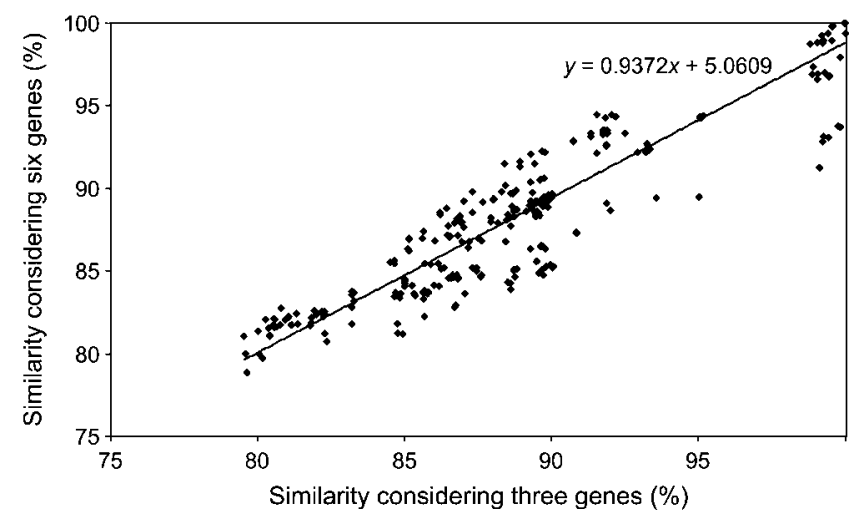

Fig. 2. Correlation between phylogenetic similarities (\%) between $P$. stutzeri strains considering six or three genes in the consensus analysis. than $98.1 \%$, except strains 2FB7A and CCUG 46542 (95.3 and $92.5 \%$, respectively). Neither strain could be assigned to any known genomovar and both were suspected to represent novel genomovars.

Strain 2FB7A has a minimal similarity to the closest genomovar of $95.3 \%$, in the range expected for a novel genomovar, although, in the topology of the 16S rRNA, $r p o D$ and $g y r B$ gene trees, the closest strains located in the same branch are DSM 50238 (gv. 7), AER 2.7 (gv. 7) and the novel strain 4FB3. For that reason, DNA-DNA hybridization experiments were done with the reference strain of gv. 7 and with the type strain of the species, strain CCUG $11256^{\mathrm{T}}$, to demonstrate that strain $2 \mathrm{FB} 7 \mathrm{~A}$ is a member of gv. 7. DNA-DNA relatedness values were calculated in duplicate using a non-radioactive method as described by Ziemke et al. (1998). DNA was isolated by the method of Marmur (1961). Reference DNAs were doublelabelled with DIG-11-dUTP and biotin-16dUTP using a nick translation kit (Boehringer Mannheim). Pooled standard deviations of the different experiments were between 0.8 and $1.2 \%$. Results are indicated in Table 2 . The four strains affiliated with the same sub-branch as the 
Table 2. DNA-DNA relatedness values (\%)

\begin{tabular}{|c|c|c|c|c|c|}
\hline \multirow[t]{2}{*}{ Source of unlabelled DNA } & \multicolumn{5}{|c|}{ Source of labelled DNA } \\
\hline & 1 & 2 & 3 & 4 & 5 \\
\hline 1. $2 \mathrm{FB} 7 \mathrm{~A}$ & 100 & 82.8 & 100 & - & - \\
\hline 4FB3 & 88.5 & 91.5 & 99.4 & - & - \\
\hline 2. AER2.7 & 85.7 & 100 & 79.8 & - & - \\
\hline 3. DSM 50238 (gv. 7) & 85.6 & 82.1 & 100 & $33^{*}$ & - \\
\hline CCUG $11256^{\mathrm{T}}$ (gv. 1) & 63.7 & 56.6 & 61.1 & 52.4 & 50.4 \\
\hline 4. DSM 50227 (gv. 3) & - & - & $55.1^{\star}$ & 100 & 61.7 \\
\hline 5. CCUG 46542 (gv. 19) & - & - & - & 64.2 & 100 \\
\hline
\end{tabular}

- , Not done.

*Data from Guasp (1999).

reference strain of gv. 7 showed interstrain DNA-DNA relatedness values greater than $79 \%$, and relatedness below $64 \%$ with the $P$. stutzeri type strain, confirming that they represent a homogeneous genomic group.

Strain CCUG 46542 (=KMM 235) was isolated by Romanenko et al. (2005) and was suspected to represent a novel genomovar. It appeared in an isolated branch in all individual analyses of each gene, with distance values similar to those found for strains of different genomovars. Strain CCUG 46542 showed 61.7 \% DNA-DNA relatedness with the reference strain of the phylogenetically closest genomovar (gv. 3), strain DSM 50227 (92.5\% similarity in the consensus analysis), and 50.4\% DNA-DNA relatedness with the $P$. stutzeri type strain CCUG $11256^{\mathrm{T}}$. These results demonstrated that strain CCUG 46542 represents a novel genomovar within the species, and it is proposed as the reference strain for genomovar 19.

All genomovars described so far have been described on the basis of DNA-DNA hybridization values. In this paper, we show that phylogenetic analysis is a valuable tool to assign novel strains of $P$. stutzeri to already-known genomovars or to define novel ones. Of the 46 strains analysed, only one, JD4 (gv. 5), could not be assigned clearly to a genomovar by analysing only the three genes selected; however, it fits within gv. 5 when four additional housekeeping genes are included (Cladera et al., 2004). A good correspondence was found between the DNA-DNA relatedness values obtained in previous studies and the consensus phylogenetic distance. Results of 77 pairwise comparisons of 14 strains are shown in Fig. 3. A gap between $\Delta T_{\mathrm{m}}$ values of 1 and $5{ }^{\circ} \mathrm{C}$ was observed when strains of the same genomovar or from different genomovars were compared, corresponding to phylogenetic similarity of between 94 and $99 \%$.

Intergenomovar similarity values were $88.6-95.2 \%$. The closest Pseudomonas species are P. balearica (83.3-87.3\%), $P$. mendocina (78.0-82.6\%) and $P$. aeruginosa (78.4$83.9 \%)$. P. xanthomarina (84.3-91.5\%) has been described recently and is affiliated within the $P$. stutzeri phylogenetic branch. It shares with $P$. stutzeri the basic phenotypic traits of the species, and could be considered a genomovar of $P$. stutzeri, but additional biochemical tests (inability to hydrolyse starch) and physiological (ability to grow at $4{ }^{\circ} \mathrm{C}$ and in the presence of $8 \% \mathrm{NaCl}$ ) and chemotaxonomic (fatty acid composition) properties justified the proposal of a novel species (Romanenko et al., 2005).

The inclusion of novel strains reinforces and clarifies the genomovar structure of $P$. stutzeri. For instance, strains st103 and st104 clustered together with strain DNSP21, reference strain of gv. 5, in the phylogenetic trees analysed. Similarly, strains 2FB7A and 4FB3 clustered together with AER 2.7, a recognized member of gv. 7. Adding novel strains gives robustness to our knowledge of the phylogenetic relationships between genomovars.

To identify a strain as P. stutzeri, it has to have the basic phenotypic traits of the species and it has to show similarity values to a recognized strain of the species of more than $88 \%$ in concatenated or consensus analysis of the $16 \mathrm{~S}$ rRNA, gyrB and $r p o D$ genes. This value shall be higher than $96 \%$ for assignment to a given genomovar. Intermediate values have to be studied carefully, including other essential genes or the ITS1 region, or performing DNA-DNA hybridizations to the phylogenetically closest genomovar reference strain. Even though DNA-DNA hybridization cannot be excluded in studies on the taxonomy of $P$. stutzeri, there is currently a tendency in bacterial taxonomy to replace it by multigenic sequencing

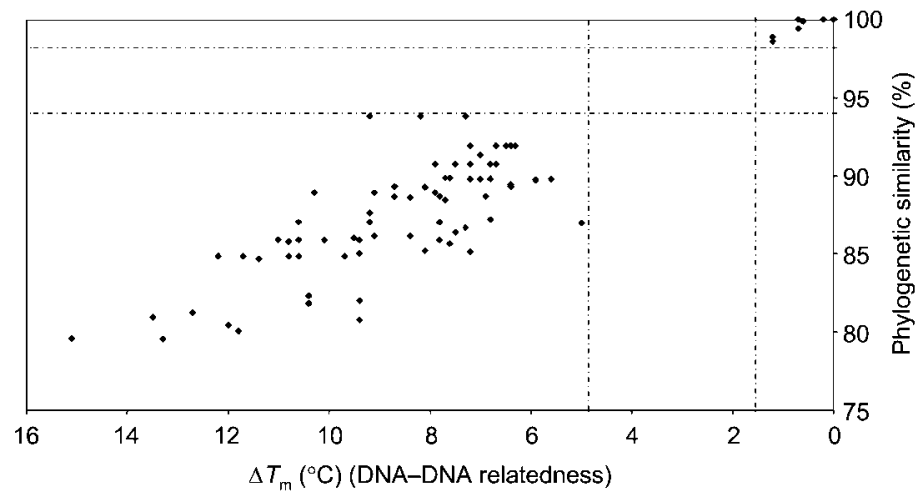

Fig. 3. Relationships between phylogenetic similarities calculated for three genes and DNA-DNA relatedness expressed as $\Delta T_{\mathrm{m}}$ $\left({ }^{\circ} \mathrm{C}\right)$. Values for $\Delta T_{\mathrm{m}}$ were taken from Rosselló et al. (1991). 
analysis, due to the latter's simplicity, portability and accuracy (Stackebrandt et al., 2002). In the present study, a good correlation has been found between phylogenetic distances and DNA-DNA relatedness values (as shown in Fig. 3) that can help in establishing objective phylogenetic values for species and genomovar discrimination in the $P$. stutzeri complex, as was shown previously in the Pseudomonas corrugata group (Cladera et al., 2006).

In a recent study presented by Goris et al. (2007), DNADNA hybridization values have been compared with the average nucleotide identity (ANI) of common genes in the analysis of complete genomes. The recommended cut-off point of $70 \%$ DNA-DNA hybridization for bacterial species delineation corresponded to an ANI of $95 \pm 0.5 \%$. In our study, the cut-off point established for genomovar discrimination is also $70 \%$ (or $5{ }^{\circ} \mathrm{C}$ difference in thermal denaturation temperature, $\Delta T_{\mathrm{m}}$ ) (Ursing et al., 1995) and it corresponded to a similarity value in the consensus matrix of $95.2 \%$. The analysis of only three housekeeping genes seems to be sufficiently discriminative for the delineation of genomovars in $P$. stutzeri, and also to differentiate $P$. stutzeri from the closest-related species.

The phylogenetic, phenotypic and biochemical diversity detected in $P$. stutzeri was also reflected when studying siderophore production. For that purpose, 17 P. stutzeri genomovar reference strains and nine novel strains were grown in the iron-poor Casamino acid medium (CAA) which is routinely used for the study of siderophore production by Pseudomonas strains. Medium composition and culture conditions were as described previously (Meyer et al., 1997). Detection of siderophores in culture supernatants was done by the chrome azurol S assay (CAS assay; Schwyn \& Neilands, 1987). Rapid siderophore characterization by $\mathrm{pH}_{\mathrm{i}}$ value was obtained through isoelectrophoresis of $1 \mu \mathrm{l}$ aliquots of 20 -fold-concentrated CAA culture supernatants, with the siderophore spots revealed by a CAS-overlay method, as described previously (Meyer et al., 2002). Cross-incorporation experiments of ${ }^{59} \mathrm{Fe}$ chelated by a siderophore produced by another strain and compared to the homologous system were performed as described previously (Meyer et al., 2002). Following growth on CAA medium, two types of siderophores were produced depending on the strains, allowing the delineation of two siderovars in P. stutzeri, as confirmed by cross-incorporation studies. Strains producing a siderophore with a spot at acidic $\mathrm{pH}\left(\mathrm{pH}_{\mathrm{i}}=4.6\right)$ were grouped in type $\mathrm{A}$ (a catecholate type): strains DSM 50238 (gv. 7), 4FB3 (gv. 7), 2FB7A (gv. 7), JM300 (gv. 8), LS401 and st101 (gv. 6, P. balearica). Strains of type B siderovar produced a siderophore with a $\mathrm{pH}_{\mathrm{i}}$ value (6.6) identical to that of pure desferriferrioxamine E (dffE): strains CCUG 11256 (gv. 1), ATCC 27951 (gv. 1), ATCC 17591 (gv. 2), DSM 50227 (gv. 3), 2FA (gv. 3), st106A (gv. 3), st107A (gv. 3), st108A (gv. 3), 19SMN4 (gv. 4), st104 (gv. 5), DNSP21 (gv. 5), st103 (gv. 5) and KC (gv. 9). The other strains studied either did not produce siderophores or they did not grow, or growth was too weak, which rendered the CAS assay and isoelectrofocusing problematic: the gv. 10 and gv. 13 reference strains did not grow in CAA medium, CCUG 46542 and the gv. 11, 14, 15, 16, 17 and 18 reference strains were CAS negative, and the reference strain of gv. 12 gave an unusual reaction, with an apparent lack of iron uptake specificity due very probably to the production of the two types of siderophore and/or siderophore receptors. $P$. xanthomarina CCUG $46543^{\mathrm{T}}$ was CAS negative.

Siderophores detected in this study are in accordance with the results obtained by Zawadzka et al. (2006), in which two types of siderophores were detected among the nine $P$. stutzeri genomovars studied: a catechol type (amonabactins), which could correspond to our type A siderophore, and a proferrioxamine type, corresponding to our type $B$ siderophore. Although it appears that siderotyping is much less discriminative within the $P$. stutzeri complex compared with the fluorescent Pseudomonas group, it is still possible to conclude that $P$. stutzeri strains belonging to the same genomovar by DNA-DNA hybridization also belong to the same siderophore group, and also that members of different genomovars can share the same siderophore. Thus, siderotyping is a good tool to differentiate species within the genus Pseudomonas and is also an argument in favour of not splitting the species $P$. stutzeri into several species, one for each genomovar.

\section{Acknowledgements}

We thank E. Falsen and W. Metcalf for their generous exchange of strains and J. Pons for advice on phylogenetic analysis. Special thanks are due to J. Arlinger and others, who isolated strain CCUG 36651, and L. A. Romanenko and others, isolators of strain CCUG 46542. A. Cladera collaborated in the first steps of this investigation. This work was supported by grants CGL2004-00838/BOS and VEM-2003-20565 from the CICYT (Spain). M. M. was the recipient of a predoctoral fellowship from the Plà Balear de Recerca i Desenvolupament Tecnològic de les Illes Balears (PRIB).

\section{References}

Cladera, A. M., Bennasar, A., Barceló, M., Lalucat, J. \& GarcíaValdés, E. (2004). Comparative genetic diversity of Pseudomonas stutzeri genomovars, clonal structure, and phylogeny of the species. J Bacteriol 186, 5239-5248.

Cladera, A. M., Sepúlveda-Torres, L. del C., Valens-Vadell, M., Meyer, J. M., Lalucat, J. \& García-Valdés, E. (2006). A detailed phenotypic and genotypic description of Pseudomonas strain OX1. Syst Appl Microbiol 29, 422-430.

Felsenstein, J. (1989). PHYLIP - phylogeny inference package (version 3.2). Cladistics 5, 164-166.

Goris, J., Konstantinidis, K. T., Klappenbach, J. A., Coenye, T., Vandamme, P. \& Tiedje, J. M. (2007). DNA-DNA hybridization values and their relationship to whole-genome sequence similarities. Int J Syst Evol Microbiol 57, 81-91.

Guasp, C. (1999). Métodos moleculares de estudio de las poblaciones de Pseudomonas stutzeri. PhD thesis, Universitat de les Illes Balears, Spain (in Spanish). 
Jukes, T. H. \& Cantor, C. R. (1969). Evolution of protein molecules. In Mammalian Protein Metabolism, vol. 3, pp. 21-132. Edited by H. N. Munro. New York: Academic Press.

Lalucat, J., Bennasar, A., Bosch, R., García-Valdés, E. \& Palleroni, N. J. (2006). Biology of Pseudomonas stutzeri. Microbiol Mol Biol Rev 70, 510-547.

Marmur, J. (1961). A procedure for the isolation of deoxyribonucleic acid from microorganisms. J Mol Biol 3, 208-218.

Metcalf, W. W. \& Wolfe, R. (1998). Molecular genetic analysis of phosphite and hypophosphite oxidation by Pseudomonas stutzeri WM88. J Bacteriol 180, 5547-5558.

Meyer, J. M. (2007). Siderotyping and bacterial taxonomy: a siderophore bank for a rapid identification at the species level of fluorescent and non-fluorescent Pseudomonas. In Soil Biology, vol. 12, Microbial Siderophores, pp. 43-66. Edited by A. Varma \& S. B. Chincholkar. Berlin \& Heidelberg: Springer.

Meyer, J. M., Stinzi, A., de Vos, D., Cornelis, P., Tappe, R., Taraz, K. \& Budzikiewicz, H. (1997). Use of siderophores to type Pseudomonas: the three Pseudomonas aeruginosa pyoverdine systems. Microbiology 143, 35-43.

Meyer, J. M., Geoffroy, V. A., Baida, N., Gardan, L., Izard, D., Lemanceau, P., Achouak, W. \& Palleroni, N. J. (2002). Siderophore typing, a powerful tool for the identification of fluorescent and nonfluorescent pseudomonads. Appl Environ Microbiol 68, 27452753.

Meyer, J. M., Gruffaz, G., Tulkki, T. \& Izard, D. (2007). Taxonomic heterogeneity, as shown by siderotyping, of strains primarily identified as Pseudomonas putida. Int J Syst Evol Microbiol 57, 2543-2556.

Miller, J. H. (1972). Assay for $\beta$-galactosidase. In Experiments in Molecular Genetics, pp. 352-355. Cold Spring Harbor, NY: Cold Spring Harbor Laboratory.

Page, R. D. M. (1996). TreeView: an application to display phylogenetic trees on personal computers. Comput Appl Biosci 12, 357-358.

Posada, D. \& Crandall, K. A. (1998). MODELTEST: testing the model of DNA substitution. Bioinformatics 14, 817-818.

Romanenko, L. A., Uchino, M., Falsen, E., Lysenko, A., Zhukova, N. V. \& Mikhailov, V. (2005). Pseudomonas xanthomarina sp. nov., a novel bacterium isolated from marine ascidian. J Gen Appl Microbiol 51, $65-71$.
Rosselló, R. A., García-Valdés, E., Lalucat, J. \& Ursing, J. (1991). Genotypic and phenotypic diversity of Pseudomonas stutzeri. Syst Appl Microbiol 14, 150-157.

Rosselló-Mora, R. A., Lalucat, J. \& Moore, E. R. B. (1996). Strain JM300 represents a new genomovar within Pseudomonas stutzeri. Syst Appl Microbiol 19, 596-599.

Schwyn, B. \& Neilands, J. B. (1987). Universal chemical assay for the detection and determination of siderophores. Anal Biochem 160, 47-56.

Sepúlveda-Torres, L. C., Zhou, J. Z., Guasp, C., Lalucat, J., Knaebel, D., Plank, J. L. \& Criddle, C. S. (2001). Pseudomonas sp. strain KC represents a new genomovar within Pseudomonas stutzeri. Int J Syst Evol Microbiol 51, 2013-2019.

Sikorski, J., Lalucat, J. \& Wackernagel, S. (2005). Genomovars 11 to 18 of Pseudomonas stutzeri identified among isolates from soil and marine sediment. Int J Syst Evol Microbiol 55, 1767-1770.

Song, B., Palleroni, N. J. \& Häggblom, M. (2000). Isolation and characterization of diverse halobenzoate-degrading denitrifying bacteria from soils and sediments. Appl Environ Microbiol 66, 34463453.

Stackebrandt, E., Frederiksen, W., Garrity, G. M., Grimont, P. A. D., Kämpfer, P., Maiden, M. C. J., Nesme, X., Rosselló-Mora, R., Swings, J. $\&$ other authors (2002). Report of the ad hoc committee for the reevaluation of the species definition in bacteriology. Int J Syst Evol Microbiol 52, 1043-1047.

Thompson, J. D., Gibson, T. J., Plewniak, F., Jeanmougin, F. \& Higgins, D. G. (1997). CLUSTAL_X windows interface: flexible strategies for multiple sequence alignment aided by quality analysis tools. Nucleic Acids Res 25, 4876-4882.

Ursing, J. B., Rosselló-Mora, R. A., García-Valdés, E. \& Lalucat, J. (1995). A pragmatic approach to the nomenclature of phenotypically similar genomic groups. Int J Syst Bacteriol 45, 604.

Yamamoto, S., Ksai, H., Arnold, D. L., Jackson, R. W., Vivian, A. \& Harayama, S. (2000). Phylogeny of the genus Pseudomonas: intrageneric structure reconstructed from the nucleotide sequences of gyrB and rpoD genes. Microbiology 146, 2385-2394.

Zawadzka, A. M., Vandecasteele, F. P. J., Crawford, R. L. \& Paszczynski, A. J. (2006). Identification of siderophores of Pseudomonas stutzeri. Can J Microbiol 52, 1164-1176.

Ziemke, F., Höfle, M. G., Lalucat, J. \& Rosselló-Mora, R. (1998). Reclassification of Shewanella putrefaciens Owen's genomic group II as Shewanella baltica sp. nov. Int J Syst Bacteriol 48, 179-186. 